\title{
Effects of umbilical cord tissue mesenchymal stem cells (UCX®) on rat sciatic nerve regeneration after neurotmesis injuries
}

\author{
Gärtner $A^{1,2^{*}}$, Pereira $T^{1,2^{*}}$, Armada-da-Silva PAS ${ }^{3,4}$, Amado $S^{4,5}$, Veloso AP ${ }^{3,4}$, Amorim $\mathrm{I}^{6,7}$, Ribeiro $\mathrm{J}^{1,2,8}$, \\ Santos $\mathrm{JD}^{9}$, Bárcia $\mathrm{RN}^{10}$, Cruz $\mathrm{P}^{10}$, Cruz $\mathrm{H}^{10}$, Luís $\mathrm{AL}^{1,2}$, Santos $\mathrm{JM}^{10}$, Geuna $\mathrm{S}^{11,12}$, Maurício $A \mathrm{C}^{1,2}$
}

\begin{abstract}
Peripheral nerves have the intrinsic capacity of self-regeneration after traumatic injury but the extent of the regeneration is often very poor. Increasing evidence demonstrates that mesenchymal stem/stromal cells (MSCs) may play an important role in tissue regeneration through the secretion of soluble trophic factors that enhance and assist in repair by paracrine activation of surrounding cells. In the present study, the therapeutic value of a population of umbilical cord tissue-derived MSCs, obtained by a proprietary method $\left(\mathrm{UCX}^{\circledR}\right)$, was evaluated on end-to-end rat sciatic nerve repair. Furthermore, in order to promote both, end-toend nerve fiber contacts and MSC cell-cell interaction, as well as reduce the flush away effect of the cells after administration, a commercially available haemostatic sealant, Floseal ${ }^{\circledR}$, was used as vehicle. Both, functional and morphologic recoveries were evaluated along the healing period using extensor postural thrust (EPT), withdrawal reflex latency (WRL), ankle kinematics analysis, and either histological analysis or stereology, in the hyper-acute, acute and chronic phases of healing. The histological analysis of the hyper-acute and acute phase studies revealed that in the group treated with UCX ${ }^{\circledR}$ alone the Wallerian degeneration was improved for the subsequent process of regeneration, the fiber organization was higher, and the extent of fibrosis was lower. The chronic phase experimental groups revealed that treatment with UCX ${ }^{\circledR}$ induced an increased number of regenerated fibers and thickening of the myelin sheet. Kinematics analysis showed that the ankle joint angle determined for untreated animals was significantly different from any of the treated groups at the instant of initial contact (IC). At opposite toe off (OT) and heel rise (HR), differences were found between untreated animals and the groups treated with either UCX ${ }^{\circledR}$ alone or $\mathrm{UCX}^{\circledR}$ administered with Floseal ${ }^{\Theta}$. Overall, the UCX ${ }^{\circledR}$ application presented positive effects in functional and morphologic recovery, in both the acute and chronic phases of the regeneration process. Kinematics analysis has revealed positive synergistic effects brought by Floseal $^{\circledR}$ as vehicle for MSCs.
\end{abstract}

Key Words: Wharton's jelly, mesenchymal stem cells, neurotmesis, myelinization, functional assessment, stereology

\section{Introduction}

A full understanding of nerve regeneration, namely complete functional achievement and organ re-innervation after nerve injury, still remains a main goal for regenerative medicine. Peripheral nerve injury has a high regenerative potential, but functional recovery rarely occurs after total nerve transection. In the peripheral nervous system, nerves can spontaneously regenerate without any treatment if nerve continuity is maintained (axonotmesis), whereas more severe type of injuries must be surgically treated by direct end-to-end surgical reconnection of the damaged nerve ends ${ }^{[1-3]}$. Cell transplantation has been proposed as a method for improving peripheral nerve regeneration ${ }^{[4]}$, including Schwann cell (SC) transplantation that can enhance axon outgrowth and survival, both in vitro ${ }^{[5]}$ and in vivo ${ }^{[6]}$. Mesenchymal stem cells (MSCs) have become one of the most interesting agents for regenerative medicine. Scientific and clinical evidence have demonstrated that MSCs have the ability to migrate to specific sites of injury or of tissue regeneration where they modulate the immune and the inflammatory responses and mobilize intrinsic cell reservoirs through a series of distinct paracrine mechanisms [7]. Furthermore, MSCs are not only capable of differentiating into tri-lineage mesenchyme cell types, such as adipocytes,

\footnotetext{
'Departamento de Clínicas Veterinárias, Instituto de Ciências Biomédicas de Abel Salazar (ICBAS), Universidade do Porto (UP), Rua de Jorge Viterbo Ferreira, no 228, 4050-313 Porto, Portugal. ${ }^{2}$ Centro de Estudos de Ciência Animal (CECA), Instituto de Ciências e Tecnologias Agrárias e Agro-Alimentares (ICETA), Rua D. Manuel II, Apartado 55142, 4051-401, Porto, Portugal. ${ }^{3}$ Faculdade de Motricidade Humana (FMH), Universidade de Lisboa (UL), Estrada da Costa, 1499-002, Cruz Quebrada - Dafundo, Portugal. ${ }^{4}$ CIPER-FMH: Centro Interdisciplinar de Estudo de Performance Humana, Faculdade de Motricidade Humana (FMH), Universidade de Lisboa (UL), Estrada da Costa, 1499-002, Cruz Quebrada - Dafundo, Portugal. ${ }^{5}$ UIS-IPL: Unidade de Investigação em Saúde da Escola Superior de Saúde de Leiria, Instituto Politécnico de Leiria, Portugal. ${ }^{6}$ Departamento de Patologia e de Imunologia Molecular, Instituto de Ciências Biomédicas de Abel Salazar (ICBAS), Universidade do Porto (UP), Rua de Jorge Viterbo Ferreira, no 228, 4050-313 Porto, Portugal. ${ }^{7}$ Instituto Português de Patologia e Imunologia Molecular da niversidade do Porto (IPATIMUP), Rua Dr. Roberto Frias s/n, 4200-465 Porto, Portugal. ${ }^{8}$ UPVET, Instituto de Ciências Biomédicas de Abel Salazar (ICBAS), Universidade do Porto (UP), Rua de Jorge Viterbo Ferreira, $n^{\circ}$ 228, 4050-313 Porto, Portugal. ${ }^{9}$ CEMUC, Departamento de Engenharia Metalúrgica e Materiais, Faculdade de Engenharia, Universidade do Porto, Rua Dr Roberto Frias, 4200-465 Porto, Portugal. ${ }^{10}$ ECBio - Research and Development in Biotechnology S.A., Rua Henrique Paiva Couceiro, 27, 2700-451 Amadora, Portugal. ${ }^{11}$ Neuroscience Institute of the Cavalieri Ottolenghi Foundation, Turin, Italy. ${ }^{12}$ Department of Clinical and Biological Sciences, University of Turin, Italy. ${ }^{*}$ These authors contributed equally for the results present in this research work.
} 
chondrocytes and osteoblasts ${ }^{[8]}$, but also into neuronal-like cells, including astrocytes, oligodendrocytes, microglial, neurons and neuroglial cells ${ }^{[9-11]}$. MSCs have been isolated from various types of adult tissues, the bone marrow being the most commonly used (BM-MSCs). Dezawa and collaborators in 2001 showed that autologous BM-MSCs were capable of differentiating into cells with Schwann cell properties ${ }^{[12,13]}$. BM-MSCs have been applied for cell-based therapies. However, factors such as the limited number of BM-MSCs available, the heterologous and non-consistent nature of bone marrow preparations, the possibility of donor site morbidity, and the decreasing number of BM-MSCs with donor age, make it imperative that alternative and more primordial MSCs sources are found. Different isolation procedures have led to umbilical cord tissue-derived MSCs (UC-MSCs) that exhibit a neuronal phenotype ${ }^{[14-17]}$ and have potential utility for the treatment of neurodegenerative diseases $[18,19]$. Interestingly, these cells, which are major histocompatibility complex (MHC) class II negative, are able to both evade and modulate the immune system ${ }^{[16]}$, making them an attractive cell source for MSC-based therapies. In addition, these cells represent a non-controversial source of primitive mesenchymal progenitor cells that can be isolated after birth, cryogenically stored, thawed, and expanded for therapeutic uses [20]. Within our group, a method to consistently isolate, expand, and cryopreserve a wellcharacterized population of human stem cells derived from the umbilical cord tissue has been developed and such cells termed as $U C X^{\circledR}{ }^{[21]}$. The isolation method has been specifically designed for clinical use and it has been recently adapted according to advanced therapy medicinal product (ATMP) standards, as defined by the guideline on the minimum quality data for certification of ATMP (EMA/CAT/486831/2008/corr, 2010) (results to be published elsewhere). More recently, the UCX ${ }^{\circledR}$ paracrine activity has been demonstrated to repress T-cell activation better than BM-MSCs and to promote the expansion of Tregs. Accordingly, the xenogenic $U C X^{\circledR}$ administration in an acute inflammation model showed that $\mathrm{UCX}^{\circledR}$ can reduce paw edema in vivo more efficiently than BM-MSCs ${ }^{[22]}$. Finally, animals treated with intra-articular (i.a.) and intra-peritoneal (i.p.) infusions of $U C X^{\circledR}$ showed faster and almost full remission of local and systemic arthritis manifestations, potentially demonstrating a potent paracrine induction of tissue regeneration ${ }^{[22]}$.

Biomaterials are known to be able to support cellular systems to either differentiate into neuroglial-like cells or to enhance their paracrine effects on the overall regenerative process. Concomitantly, biomaterials can be directly involved in the regenerative process, helping to improve the motor and sensory functional recovery, shortening the healing period and avoiding regional muscular atrophy ${ }^{[1,20,23]}$. Floseal ${ }^{\circledR}$ is a commercially available haemostatic sealant composed of collagen-derived particles and topical bovine-derived thrombin, which has been proven to control bleeding in several medical applications ${ }^{[24,25]}$. Floseal ${ }^{\circledR}$ has been previously applied in vivo in bone regeneration, associated to the synthetic graft Bonelike ${ }^{\circledR}$ and raloxifene hydrochloride, increasing osteointegration of Bonelike ${ }^{\circledR}$ granules and new bone formation ${ }^{[26]}$. In this study, we hypothesized that UCX ${ }^{\circledR}$ could be integrated surrounding the sectioned sciatic nerve (neurotmesis) and modulate the inflammatory response, including the Wallerian degeneration that occurs in the hyper- acute phase after injury ${ }^{[27]}$. We also hypothesized that Floseal ${ }^{\circledR}$ used as vehicle could help promoting end-to-end contact between nerve fibers and MSC cell-cell interactions within the suture, as well as maintaining $\mathrm{UCX}^{\circledR}$ cells within the wounded site. In order to test this hypothesis, the therapeutic value of $\mathrm{UCX}^{\circledR}$ was evaluated on end-to-end rat sciatic nerve repair after neurotmesis in the hyper-acute and acute healing phases since the Wallerian degeneration occurring during the first days after the injury is crucial for an effective regeneration. On the other hand, a functional and morphometric analysis in the chronic phase allowed for the evaluation of the actual nerve regeneration. Overall, our results suggest that the application of $\mathrm{UCX}^{\circledR}$ and Floseal ${ }^{\circledR}$ presented synergistic positive effects in functional and morphological recoveries in the overall nerve regeneration process.

\section{Materials and methods}

\subsection{Ethics and regulation}

Umbilical cord donations were obtained with written informed consents according to Directive 2004/23/EC, which sets the standards of quality and safety for the donation, procurement, testing, processing, preservation, storage and distribution of human tissues and cells. All the animal testing procedures were in conformity with the Directive 2010/63/EU of the European Parliament and with the approval of the Veterinary Authorities of Portugal in accordance with the European Communities Council Directive of November 1986 (86/609/EEC). Humane end points were followed in accordance to the OECD Guidance Document on the Recognition, Assessment and Use of Clinical Signs as Humane Endpoints for Experimental Animals Used in Safety Evaluation (2000). Adequate measures were taken to minimize pain and discomfort taking into account human endpoints for animal suffering and distress. Animals were housed for two weeks before entering the experiment.

\subsection{UCX ${ }^{\circledR}$ Isolation and Culture}

Cells were isolated from the umbilical cord tissue as in Santos et al. 2008 (INPI 103843, PCT/IB2008/054067, $\mathrm{WO} / 2009 / 044379$ ) with a number of minor alterations. Briefly, after $24 \mathrm{~h}$ in contact with a saline solution containing antibiotics and anti-mycotics, umbilical cords were cleared of blood clots and transversely sectioned in $2.5 \mathrm{~cm}$ portions. These pieces were subsequently treated with a digestion solution containing collagenase and trypsin, for $4 \mathrm{~h}$ at $37^{\circ} \mathrm{C}$ after which cells were allowed to adhere to the lower surface of a t-flask for $30 \mathrm{~min}$. After this time, the liquid media was collected and centrifuged at $200 \mathrm{~g}$ at $4^{\circ} \mathrm{C}$ for $5 \mathrm{~min}$, supernatant was collected and returned to the original t-flask and the pellet was discarded. The isolated cells were maintained in a humidified chamber at $37^{\circ} \mathrm{C}$ and $7 \% \mathrm{CO}_{2}$, cells were subject to regular medium replacements and maintained until $80 \%$ of confluency. The MSCs phenotype was confirmed by flow cytometry. Detection was performed with the following antibodies and their respective isotypes (all from BioLegend unless stated otherwise): PE anti-human CD105 (eBioScience); APC anti-human CD73; PE antihuman CD90; PerCP/Cy5.5 anti-human CD45: FITC antihuman CD34;; PerCP/Cy5.5 anti-human CD14; Pacific Blue anti-human CD19 and pacific-blue anti-human HLA-DR. 
$\mathrm{UCX}^{(B)}$ were maintained in culture in a-MEM (Minimum Essential Medium Eagle's Alpha Modification, Sigma - Aldrich) with $2 \mathrm{mM}$ glutamine, supplemented with $20 \%$ FBS (heat inactivated Fetal Bovine Serum, Invitrogen ${ }^{\mathrm{TM}}$ ) at $37^{\circ} \mathrm{C}$ in a $5 \% \mathrm{CO}_{2}$, humid environment. For cell passage, PBS (Dulbecco's Phosphate Buffered Saline, Sigma-Aldrich) was used prior to trypsinization to wash cells, followed by contact with TrypLETM Select (Invitrogen $^{\mathrm{TM}}$ ). TrypLE ${ }^{\mathrm{TM}}$ Select was inactivated by addition of PBS and subsequent centrifugation at $200 \mathrm{~g}$ for $10 \mathrm{~min}$ (Sartorius, Model: 2-6). Seeding density was $1 \times 10^{4} \mathrm{cells} / \mathrm{cm}^{2}$, unless indicated otherwise. Cell viability was evaluated using the trypan blue (Sigma-Aldrich) exclusion method (Figures $1 \mathrm{~A}$ and $1 \mathrm{~B}$ ).

\subsection{UCX ${ }^{\circledR}$ Tri-Lineage Differentiation}

To induce adipogenic differentiation, $\mathrm{UCX}^{\circledR}$ were cultured for 3 days in adipogenic differentiation medium, consisting of a-MEM supplemented with $20 \%$ FBS, $2 \mathrm{mM}$ L-glutamine, $10 \mu \mathrm{g} / \mathrm{mL}$ insulin (Sigma-Aldrich), $200 \mu \mathrm{M}$ indomethacin (Sigma-Aldrich), $0.5 \mathrm{mM}$ isobutylmetylxantine (Sigma-Aldrich), and $1 \mu \mathrm{M}$ dexamethasone (Sigma-Aldrich); and subsequently 1 day in adipogenic maintenance medium, consisting of $\alpha-M E M$ supplemented with $20 \%$ FBS, $2 \mathrm{mM} \mathrm{L}$-glutamine and $10 \mu \mathrm{g} / \mathrm{mL}$ insulin. Medium was replaced every 3 days during 21 days, after which histochemical staining was performed. For chondrogenic differentiation, cells were grown in suspension as pellets, incubated in chondrogenic differentiation medium consisting on DMEM-LG (Sigma-Aldrich), 1\% FBS, 2 mM L- glutamine, $6.25 \mu \mathrm{g} / \mathrm{mL}$ insulin (Sigma-Aldrich), $10 \mathrm{ng} / \mathrm{mL}$ TGF- $\beta 1$ (Tebu-bio), and $50 \mu \mathrm{M}$ ascorbate-2-phosphate (Sigma-Aldrich). Finally, to induce osteogenic differentiation, cells were incubated in osteogenic differentiation medium whose composition is a-MEM, 10\% FBS, $1 \mathrm{~g} / \mathrm{L}$ glucose, 2 $\mathrm{mM}$ glutamine, $10 \mathrm{mM} \beta$-glycerol phosphate, $50 \mu \mathrm{g} / \mathrm{mL}$ ascorbate-2-phosphate, and $100 \mathrm{nM}$ dexamethasone (all reagents are from Sigma-Aldrich). The medium was replaced every 3 days during 21 days and histochemical staining was performed. In adipogenic and osteogenic differentiation protocols, cells were washed and fixed with paraformaldehyde $4 \%$ for 20 min and stained with oil red $O$ and alkaline phosphatase, respectively. For chondrogenic differentiation, cells were also fixed in paraformaldehyde $4 \%$, dried, embedded in paraffin and cut into sections and finally stained with alcian blue. The presence of stained cells was confirmed by inverted microscopy with phase contrast (Leica, DMIL HC) (Figure 1C).

\subsection{Vehicle preparation and $U C X^{\circledR}$ association}

Floseal $^{\circledR}$ is a ready-to-use commercial hemostatic matrix, also applied in neurosurgery; the application kit consists of a bovine-derived gelatin matrix, a human derived thrombin component, applicator tips and several mixing accessories. Floseal $^{\circledR}$ is biocompatible and resorbed within 6 to 8 weeks. The preparation of the Floseal ${ }^{\circledR}$ prior to use followed the manufacture instructions (www.floseal.com). Briefly, using the $5 \mathrm{ml}$ syringe with needle-attached provided in the

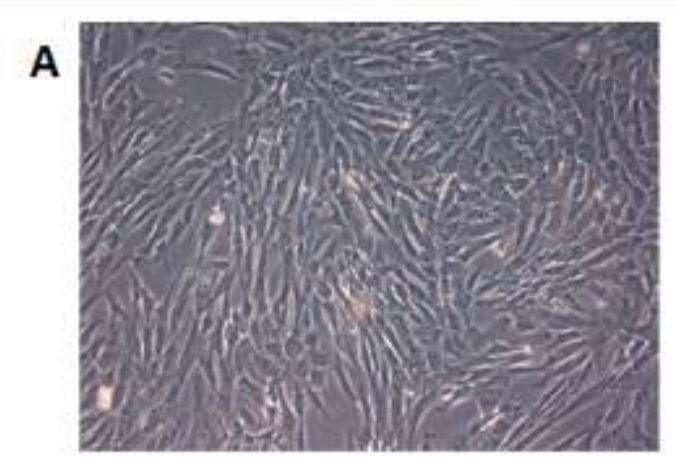

B
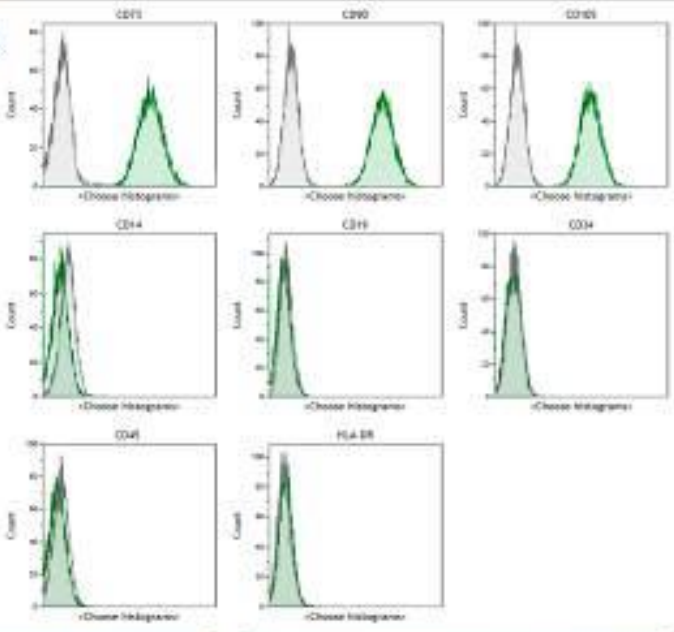

II

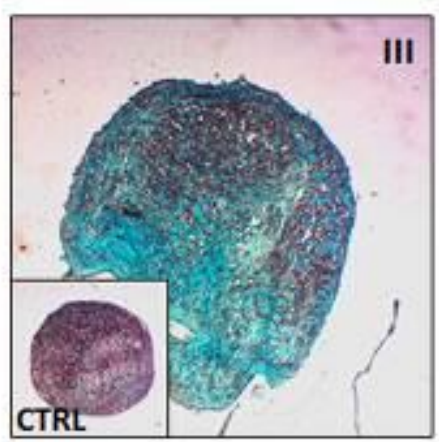

Figure 1 - UCX $X^{(B)}$ characterization. Isolated $U C X^{(B)}$ presented a fusiform, fibroblast-like morphology in culture $(A)$. Results from Flow Cytometry analysis of cell surface markers are presented as histograms (B). Multi-lineage differentiation potential of UCX ${ }^{B}$ was qualitatively analyzed by histological staining methods (C). Adipogenic differentiation was assessed with Oil Red O staining (C, i); osteogenic differentiation with Alkaline Phosphatase staining (C, ii) and chondrogenic differentiation with Alcian Blue staining (C, iii). 
thrombin component package, the $5 \mathrm{ml}$ chloride solution is transferred to the vial containing the thrombin. The dissolved thrombin is aspirated from the small bowl into the syringe to the indicated mark $(4 \mathrm{ml})$ and the gelatin matrix granules syringe is connected to the syringe containing the thrombin solution and the gelatin matrix - thrombin solution mixture is transferred back and forth between the syringes for a total of 10 passes (Figure $2 \mathrm{~A}$ ).

Intracellular free $\mathrm{Ca}^{2+}$ concentration $\left(\left[\mathrm{Ca}^{2+}\right]_{\mathrm{i}}\right)$ was measured in Fura-2-loaded MSCs by using dual wavelength spectrofluorometry as previously described [1]. The measurements were performed on UCX ${ }^{\circledR}$ cells mixed with Floseal ${ }^{\circledR}$ on discs in order to correlate MSC survival capacity with the presence of Floseal ${ }^{\circledR}$. Results obtained from epifluorescence technique are referred to measurements from UCX ${ }^{\circledR}$ cells which correspond to $\left[\mathrm{Ca}^{2+}\right]_{i}$ from cells that did not begin the apoptosis process (data not shown). According to these results, it is reasonable to conclude that Floseal $^{\circledR}$ is a viable substrate for local delivery of undifferentiated MSCs into the nerve injury.

\subsection{Microsurgical procedure}

Adult male Sasco Sprague Dawley rats (Charles River Laboratories, Barcelona, Spain) weighing 250-300 g, were randomly divided into groups of 6 to 7 animals each. For surgery, animals were placed prone under sterile conditions and the skin from the clipped lateral right thigh scrubbed in a routine fashion with antiseptic solution. The surgeries were performed under an M-650 operating microscope (Leica Microsystems, Wetzlar, Germany). Under deep anesthesia (ketamine $90 \mathrm{mg} / \mathrm{Kg}$; xylazine $12.5 \mathrm{mg} / \mathrm{Kg}$, atropine 0.25 $\mathrm{mg} / \mathrm{Kg}$ i.m.), the right sciatic nerve was exposed through a skin incision extending from the greater trochanter to the midthigh distally followed by a muscle splitting incision. After nerve mobilization, a transection injury was performed (neurotmesis) immediately above the terminal nerve ramification using straight microsurgical scissors. For the acute phase study, animals were randomly assigned to 3 experimental groups. In the first group (End-to-End), immediate cooptation with $7 / 0$ monofilament nylon epineural sutures of the 2 transected nerve endings. In the second group (End-to-EndUCX group) the animals received the same treatment as the previous group, but the injury local was infiltrated with $\mathrm{UCX}^{\circledR}$ suspended in culture medium. The third group was composed of 6 healthy animals without any injury (Control). For these groups, animals were euthanized 21 days (week 3 ) after the neurotmesis injury and surgery procedure. Animals were then randomly assigned to five experimental groups, and included in the chronic phase study. In a first group (End-to-End), immediate cooptation with $7 / 0$ monofilament nylon epineural sutures of the 2 transected nerve endings was performed. In a second group (End-to-EndFlosealUCX group), nerve transaction was reconstructed by end-to-end suture, like in the first group, and then locally enwrapped with $U C X^{\circledR}$ mixed with Floseal ${ }^{\circledR}$. In a third group (End-to-EndUCX group) animals received the same treatment as the previous group, but locally infiltrated with $U C X^{\circledR}$ alone, suspended in culture medium. In a fourth group (End-to-EndFloseal group), animals received the same treatment as the previous group, but locally enwrapped with Floseal ${ }^{\circledR}$ alone. Also, a group of 6 animals without any injury was included (Control).
For these groups, animals were euthanized 20 weeks after the neurotmesis injury and surgery procedure. In both studies, 5000 viable UCX ${ }^{\circledR}$ cells were applied / neurotmesis lesion in a volume of $20 \mu \mathrm{l}$ of culture medium. In order to also evaluate the effect of UCX ${ }^{\circledR}$ in the hyper-acute phase of the healing period, 4 more animals were euthanized 3 days after the surgical procedure for repairing the neurotmesis lesion and submitted to histological analysis: end-to-end suture (End-to-End), end-to-end suture covered by Floseal ${ }^{\circledR}($ Endto-EndFloseal), end-to-end suture infiltrated with $\mathrm{UCX}^{\circledR}$ (Endto-End $\cup C X)$, and end-to-end suture with $U C X^{\circledR}$ mixed with Floseal ${ }^{\circledR}$ (End-to-EndFlosealUCX). In this experimental group, 5000 viable $\mathrm{UCX}^{\circledR}$ cells were also applied in the neurotmesis lesion either suspended in $20 \mu \mathrm{l}$ of culture medium or in the appropriate vehicle $\left(\right.$ Floseal $^{\circledR}$ ). UCX ${ }^{\circledR}$ cells were either infiltrated into the interfascicular epineurium in the End-to-EndUCX groups or placed in contact to the external side of the nerve epineurium in the End-toEndFlosealUCX groups. These surgical procedures limited the systemic dissemination of the MSCs and improved the local application of these MSCs in the injury site. Since all the experimental animals are euthanized after the healing period of 3 days, 3 weeks and 20 weeks for the hyper-acute, acute and chronic study, respectively, the same animals were not used in the three different healing period studies. To prevent autotomy, a deterrent substance was applied to the animals' right paw ${ }^{28,29]}$. The animals were intensively examined for signs of autotomy and contracture post-operative and none presented severe infections (Figures 2B, 2C and 2D).

\subsection{Functional assessment}

The chronic phase groups (End-to-End; End-toEndFlosealUCX; End-to-EndUCX; End-to-EndFloseal, Control) were tested pre-operatively (week 0 ), at week 1 and then, every 2 weeks until the end of follow-up time (20 weeks). The acute phase group (End-to-End, End-toEndUCX, and Control) were tested pre-operatively (week 0), and at days 7 (week 1), 14 (week 2) and 21 (week 3). Animals were gently handled, and tested in a quiet environment to minimize stress. No functional assessment was performed in the hyper-acute phase experimental group.

\section{Evaluation of motor performance (EPT) and nociceptive function (WRL)}

Motor performance and nociceptive function were evaluated by measuring extensor postural thrust (EPT) and withdrawal reflex latency $(\mathrm{WRL})$, respectively. The animals were tested pre-operatively (week 0), at day 7 (week 1), 14 (week 2), and 21 (week 3) (Acute phase study); and pre-operatively (week 0 ) and were tested pre-operatively (week 0), at week 1 and afterwards, every 2 weeks until the end of follow-up time (20 weeks) (Chronic phase study). The EPT was originally proposed by Thalhammer and collaborators, in $1995^{\text {[30] }}$ as part of the neurological recovery evaluation in the rat after sciatic nerve injury. For this test, the entire body of the animal, with exception of the hind-limbs, is wrapped in a surgical towel. EPT is induced by supporting the animal by the thorax and lowering the affected hind-limb towards the platform of a digital balance. As the animal is lowered to the platform, it extends the hind-limb, anticipating the contact made by the distal metatarsus and digits. 

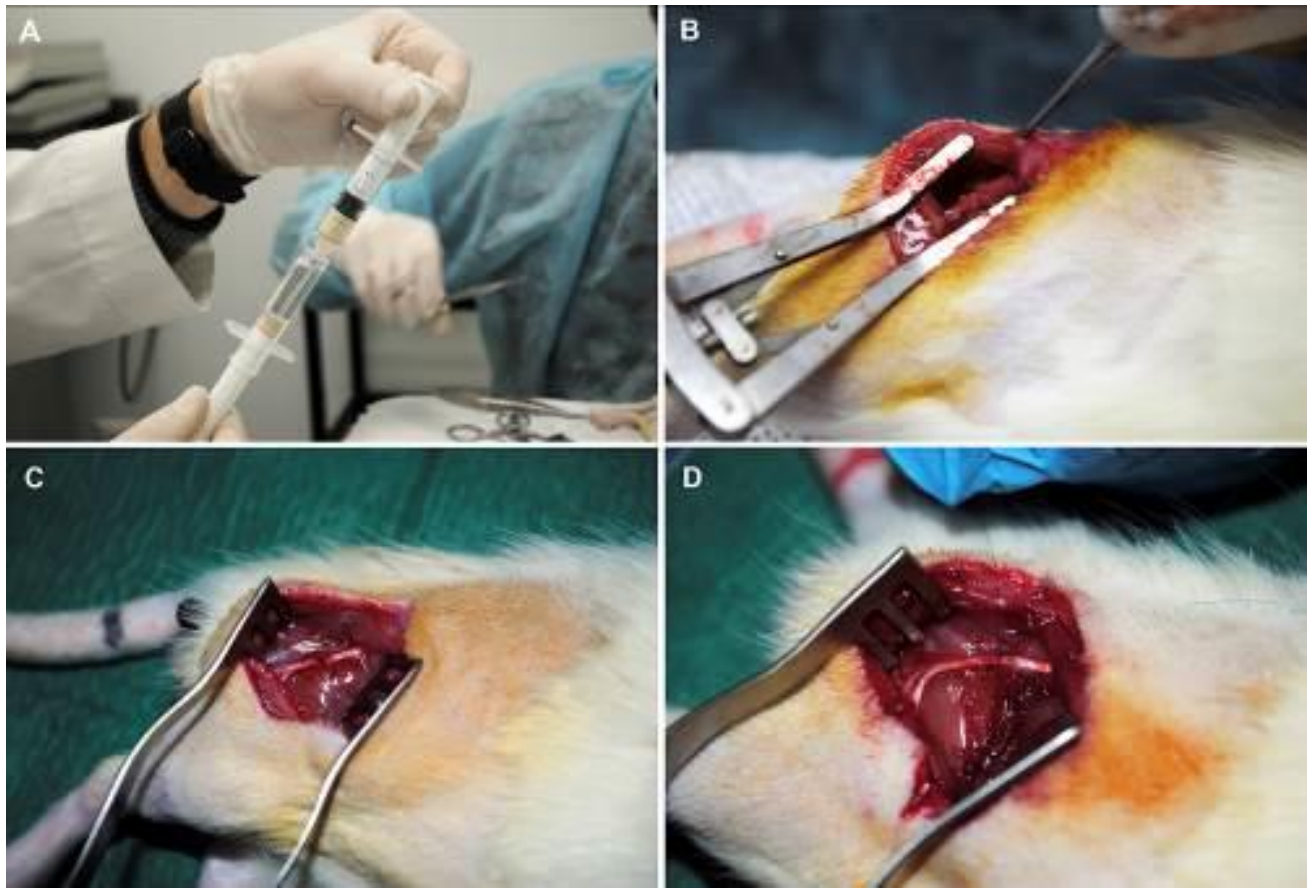

Figure 2 - Floseal ${ }^{(i)}$ preparation, rat sciatic nerve injury and surgical reconstruction. The $5 \mathrm{ml}$ chloride solution is transferred to a vial containing thrombin. The vial is gently swirled until the thrombin is dissolved. The dissolved thrombin is aspirated from the small bowl into the syringe to the indicated mark (4 ml) and the gelatin matrix granules syringe is connected to the syringe containing the thrombin solution and the gelatin matrix - thrombin solution mixture is transferred back and forth between the syringes for a total 10 passages $(A)$. Rat sciatic nerve reconstructed with an end-to-end suture and Flosea ${ }^{\circledR}$ (End-toEndFloseal group) (B). Rat sciatic nerve with a neurotmesis injury with a gap of $10 \mathrm{~mm}(C)$. The neurotmesis injury was performed and regeneration initiated after reconstruction with an end-to-end suture where the coaptation was performed with 7/0 monofilament nylon epineural sutures of the 2 transected nerve endings (D).

The force in grams $(\mathrm{g})$ applied to the digital platform balance is recorded. The same procedure is applied to the contralateral, unaffected limb. For the EPT test, the affected and normal limbs are tested 3 times, with an interval of 2 minutes between consecutive tests, and the 3 values are averaged to obtain a final result. The normal (unaffected limb) EPT (NEPT) and experimental EPT (EEPT) values are incorporated into an equation (Equation (1)) to derive the percentage of functional deficit, as described in the literature [23, 31-34]

$\%$ Motor deficit $=[($ NEPT - EEPT $) /$ NEPT $] \times 100$

To assess the nociceptive withdrawal reflex (WRL), the hotplate test was modified as described by Masters and collaborators ${ }^{[35]}$. The animal is wrapped in a surgical towel above its waist and then positioned to stand with the affected hind paw placed on a hot plate, at $56^{\circ} \mathrm{C}$, and with the other on a room temperature plate. WRL is defined as the time elapsed from the onset of hotplate contact to withdrawal of the hind paw and measured with a stopwatch. Normal animals withdraw their paws from the hotplate within $4.3 \mathrm{~s}$ or less ${ }^{[1,23,34,36]}$. The affected limbs were tested 3 times, with an interval of 2 min between consecutive tests to prevent sensitization, and the three latencies were averaged to obtain a final result ${ }^{[37]}$. If there was no paw withdrawal after $12 \mathrm{~s}$, the heat stimulus was removed to prevent tissue damage, and the animal was assigned the maximal WRL of $12 \mathrm{~s}^{[38,39]}$.

\section{Kinematics analysis}

Ankle kinematics was carried out prior nerve injury (week 0), and at the 20-week follow-up time and it was only performed in the chronic phase study in the following experimental groups: End-to-End, End-to-EndFlosealUCX, End-toEndUCX, and End-to-EndFloseal group.
Also, a group of 6 animals without any injury was included (Control). Animals walked on a Perspex track with length, width and height of 120,12 , and $15 \mathrm{~cm}$, respectively. In order to ensure locomotion in a straight line, the width of the apparatus was adjusted to the actual animal size during the experiments. The animals' gait was video recorded at a rate of 300 images per second (Casio Exilim PRO EX-F1, Japan). The camera was positioned at the track half-length where gait velocity was steady, and $1 \mathrm{~m}$ distant from the track obtaining a visualization field of $14 \mathrm{~cm}$ wide. The video images were stored in a computer hard disk for later analysis using an appropriate software APAS $^{\circledR}$ (Ariel Performance Analysis System, Ariel Dynamics, San Diego, USA). 2-D biomechanical analysis (sagittal plan) was carried out applying a two-segment model of the ankle joint, adopted from the model firstly developed by Varejão ${ }^{[40]}$. The animals' ankle angle was determined using the scalar product between a vector representing the foot and a vector representing the lower leg. With this model, positive and negative values of position of the ankle joint $\left(\theta^{\circ}\right)$ indicate dorsiflexion and plantarflexion, respectively. For each step cycle the following time points were identified: Initial Contact (IC), Opposite Toe-off (OT), and Heel Rise (HR) and Toe-off (TO) ${ }^{[40-42]}$ and were time normalized for $100 \%$ of step cycle. The normalized temporal parameters were averaged over all recorded trials. A total of 6 walking trials for each animal with stance phases lasting between 150 and 400 milliseconds were considered for analysis, since this corresponds to the animal's normal walking velocity $(20-60 \mathrm{~cm} / \mathrm{s})^{[40]}$.

\subsection{Sciatic nerve stereology and histological analysis}

For the chronic phase study, histomorphometric analysis was performed. Nerve samples obtained from the 10-mm-long 
sciatic nerve segments distal to the neurotmesis site and from un-operated controls were processed for quantitative morphometry of myelinated nerve fibers [43]. Fixation was carried out using $2.5 \%$ purified glutaraldehyde and $0.5 \%$ saccarose in $0.1 \mathrm{M}$ Sorensen phosphate buffer for $6-8$ hours and resin embedding was obtained following Glauerts' procedure ${ }^{[44]}$. Series of about 50 semi-thin transverse sections $(2-\mu \mathrm{m}$ thick) were cut using a Leica Ultracut UCT ultramicrotome (Leica Microsystems, Wetzlar, Germany) starting from the distal end of the specimen and stained by Toluidine blue. Stereology was carried out on one section, randomly selected from each of these series, using a DM4000B microscope equipped with a DFC320 digital camera and an IM50 image manager system (Leica Microsystems, Wetzlar, Germany). Systematic random sampling and D-dissector were adopted using a protocol previously described $[45,46]$. Fiber density and total number were estimated together with fiber and axon diameter and myelin thickness. For the acute phase study, the animals were euthanized 21 days after surgery and the samples' histological preparation was as described for the histomorphometric analysis. For the hyper-acute phase study the nerve samples were collected at day 3 , fixed in $10 \%$ buffered formalin, routinely processed, dehydrated and embedded in paraffin wax. Consecutive $4 \mu \mathrm{m}$-sections were cut, stained with haematoxylin and eosin (HE) and submitted to histological evaluation where a quality analysis was performed by a single operator.

\subsection{Statistical analysis}

For data regarding the functional tests, means and standard deviations (SD) were computed and reported for each time point, including pre-operatively, and each experimental group. Differences between time points and between groups were tested by two-way analysis of variance (ANOVA) using a mixed model of within- (time of recovery) and betweensubjects (experimental groups) factors. In case ANOVA revealed an overall significant main effect of experimental group (between-subjects factor), pair-wise comparisons between the groups was undertaken using the post hoc Tukey's HSD test. For stereology, statistical comparisons of quantitative data were subjected to one-way ANOVA test. All statistical procedures were performed by using the statistical package SPSS (version 17.0, SPSS, Inc) except stereological data that were analyzed using the software "Statistica per discipline bio-mediche" (McGraw-Hill, Milan, Italy). All data in this study are presented as mean \pm SD. Statistical significance was accepted at $p<0.05$.

\section{Results}

\subsection{UCX ${ }^{\circledR}$ cells are Mesenchymal Stem Cells (MSCs) according to the ISCT}

MSCs, as defined by the International Society for Cellular Therapy (ISCT), are cells characterized by: a) their capacity to adhere to plastic; b) expression of specific surface markers, namely , CD73, CD90, and CD105, and no expression of CD14, CD19, CD34, CD45 and HLA-DR. Additionally, according to the ISCT, MSCs are able to undergo tri-lineage differentiation into adipocytes, chondrocytes and osteoblasts ${ }^{[47]}$. UCX ${ }^{\circledR}$ cells were expanded to P5 where the culture appeared homogeneous and cells presented their typical fusiform, fibroblast-like, morphology (Figure 1A). As expected for MSC-type stem cells, flow cytometry analysis showed that over $95 \%$ of the cells in the population were consistently positive for the cell surface markers CD44, CD73, CD90 and CD105 and less than 2\% positive for CD14, CD19, CD31, CD34, CD45 and HLA-DR (Figures $1 \mathrm{~B})$. In order to assay for $U C X^{\circledR}$ capacity for trilineage differentiation, $U C X{ }^{\circledR}$ expanded to $P 5$ were incubated with specific differentiation media as described in the methods section. Results showed that $U_{C X}{ }^{\circledR}$ cells have the capacity for tri-lineage differentiation into adipocytes, chondrocytes and osteoblasts (Figures 1C i, ii, iii). Together these results show that $U C X^{\circledR}$ meet the minimum definition criteria of MSCs, according to the ISCT.

\subsection{Motor deficit and Nociception function}

For the acute study, at week 1 following sciatic nerve transection and end-to-end repair, every animal reached the $12-\mathrm{sec}$ end point of the WRL test, which is compatible with complete sensory loss in the plantar skin territory innervated by sciatic nerve. During the following weeks, withdrawal response latency improved, although at faster rate in the End-to-End group, compared with the End-to-EndUCX group $(p=0.000$; Figure 7A). Motor deficit in the immediate week following sciatic nerve transection and end-to-end repair reached values close to maximum (i.e., close to 1.0, compatible with complete absence of motor response in the affected hind-limb during the EPT test). Thereafter, the EPT response in the affected hind-limb somewhat improved until the end of week 3, particularly in the End-to-End group (Endto-End group vs. End-to-EndUCX group, $\mathrm{p}=0.000$; Figure 7B).
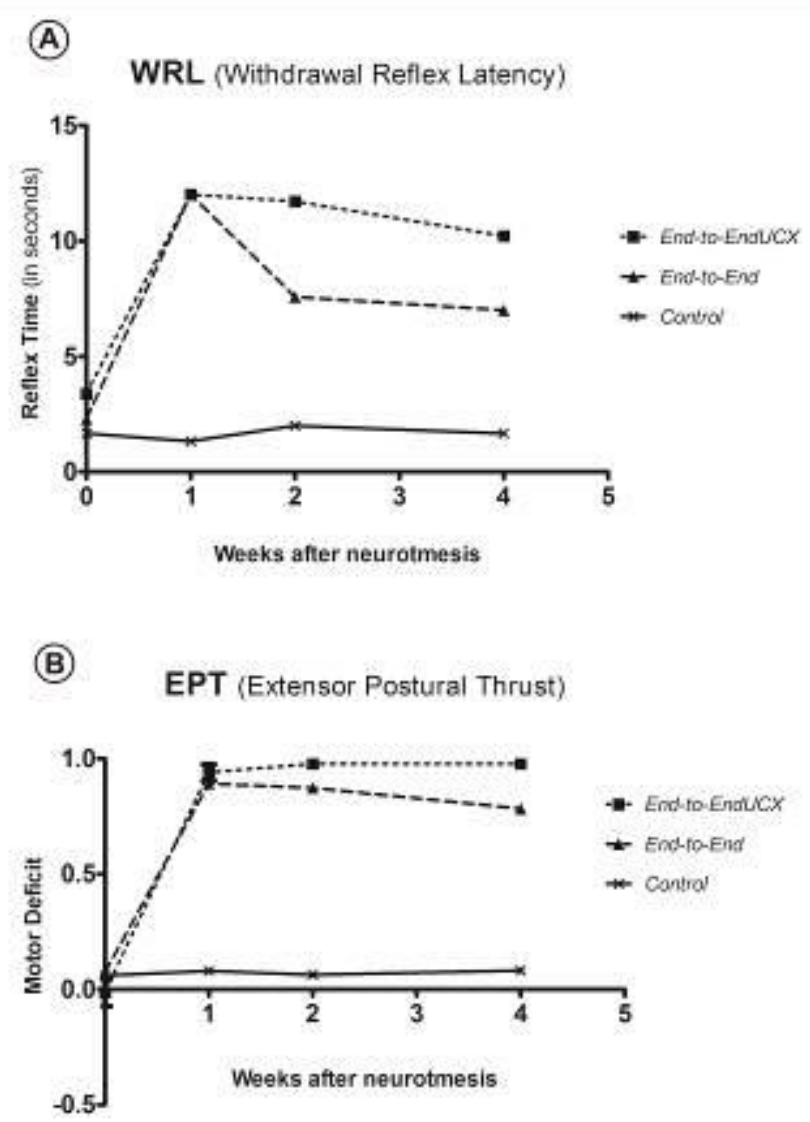

Figure 7 - Mean Withdrawal Reflex Latency (WRL) and Extensor Postural Thrust (EPT) results for acute phase. Values in seconds (s) were obtained performing the Withdrawal Reflex Latency (WRL) test to evaluate the nociceptive function (A). Values of Motor Deficit were obtained performing Extensor Postural Thrust (EPT) test (B). Both tests were performed preoperatively (week 0), at day 7 (week 1), day 14 (week 2) and day 21 (week 3). The animals were sacrificed for morphological analysis at day 21 (week 3). 
For the chronic study groups, data from WRL were analyzed through two-way Anova for repeated measures, comparing groups after sciatic neurotmesis treated with UCX ${ }^{\circledR}$ (End-toEndUCX group), Floseal ${ }^{\circledR}$ (End-to-EndFloseal group), these two treatments combined (End-to-EndFlosealUCX group) and an end-to-end control group (End-to-End). The results showed a significant interaction effect between time of recovery and treatment $[F(33,220)=3.097 ; p=0.000]$. This effect was explained by differences in recovery of the WRL after sciatic nerve neurotmesis between the end-to-end group (End-to-End) and the remaining experimental groups, with the former animals showing better recovery in this test. No differences in WRL recovery were found among animals treated with Floseal ${ }^{\circledR}$ (End-to-EndFloseal group), MSCs (End-to-EndUCX group) or with combined Floseal $^{\circledR}$ plus UCX $^{\circledR}$ (End-to-EndFlosealUCX group) (Figure 8A). As a matter of fact, the Floseal ${ }^{\circledR}$ did not improve the functional recovery when associated to the cellular system and when applied alone to the surgically reconstructed nerve, probably due to the gelatine matrix and the thrombin component, that works as glue, allowing for a tight contact between the two nerve stumps but not promoting the MSCs survival or growth factors and cytokines production in the injury site.

The fact that the End-to-EndFloseal group and the End-toEndFlosealUCX group have reached normal values in terms of WRL, has demonstrated that our vehicle choice was successful.The potential added value of $U C X^{\circledR}$ in the chronic model was not noticeable by measuring WRL alone, although the End-to-EndUCX group also reached normal WRL values of at week 20.

(A)

\section{WRL (Withdrawal Reflex Latency)}

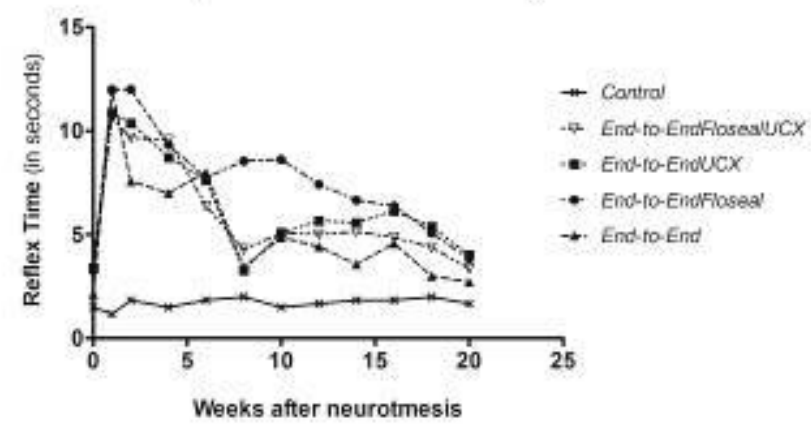

(B)

EPT (Extensor Postural Thrust)

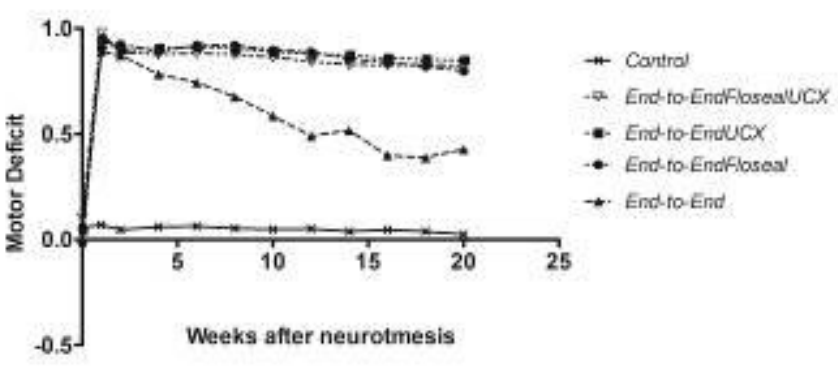

Figure 8 - Mean Withdrawal Reflex Latency (WRL) and Extensor Postural Thrust (EPT) results for 20 weeks follow-up. Values in seconds (s) were obtained performing Withdrawal Reflex Latency (WRL) test to evaluate the nociceptive function (A). Values of Motor Deficit were obtained performing Extensor Postural Thrust (EPT) test (B). This test has been performed pre-operatively (week 0), at week-1 and every 2 weeks after the surgical procedure until week 20, when the animals were sacrificed for morphological analysis.
As for EPT, no differences in recovery were found among animals treated with Floseal ${ }^{\circledR}$ (End-to-EndFloseal group), $\mathrm{UCX}^{\circledR}$ (End-to-EndUCX group) or with combined Floseal ${ }^{\circledR}$ plus $U_{C X}{ }^{\circledR}$ (End-to-EndFlosealUCX group), with all treated groups presented elevated motor deficit at week 20, of $0.82 \pm 0.07,0.87 \pm 0.03$, and $0.86 \pm 0.04$, respectively (Figure $8 \mathrm{~A}$ and $8 \mathrm{~B}$ ). These values were due to autotomy and contractures developed during the healing period although a deterrent substance was applied to animals' right foot every 48 hours ${ }^{[28,29]}$ (Figure 8B).

\subsection{Kinematics analysis}

Ankle joint kinematics during gait was assessed in the experimental treated groups at the end of the 20-weeks recovery time and was compared with data from uninjured control animals. Ankle angle was compared between groups at four selected instants belonging to the stance phase and significant differences between the groups were found for each of these time points, except for TO. Post hoc pair-wise comparisons showed that no differences in ankle joint angle existed between the uninjured control group and any of the sciatic-treated groups. However, differences in this parameter existed between experimental groups. At the instant of IC, the ankle joint angle was significantly different when comparing the End-to-End group to any of the remaining sciatic-treated groups (End-to-EndFlosealUCX, End-to-EndUCX and End-to-EndFloseal) ( $\mathrm{p}<0.05)$. At OT, which occurs around $20 \%$ of the entire stance phase duration, differences between groups were now found between the End-to-End and End-to-EndUCX ( $\mathrm{p}=0.023)$, and End-to-EndFlosealUCX $(p=0.005)$, as well as between the two latter groups $(p=0.015)$. Further differences in ankle angle at this time point were observed between the End-toEnd group and the group treated with $U C X^{\circledR}$ and Floseal ${ }^{\circledR}$ (End-to-EndFlosealUCX) $(\mathrm{p}=0.038)$. At the instant of HR, meaning the time during the stance phase of the rat's gait cycle when the push off action begins, significant differences in ankle joint angle existed between End-to-EndFloseal animals and those within the End-to-EndFlosealUCX group $(p=0.008)$ (Figure 3).

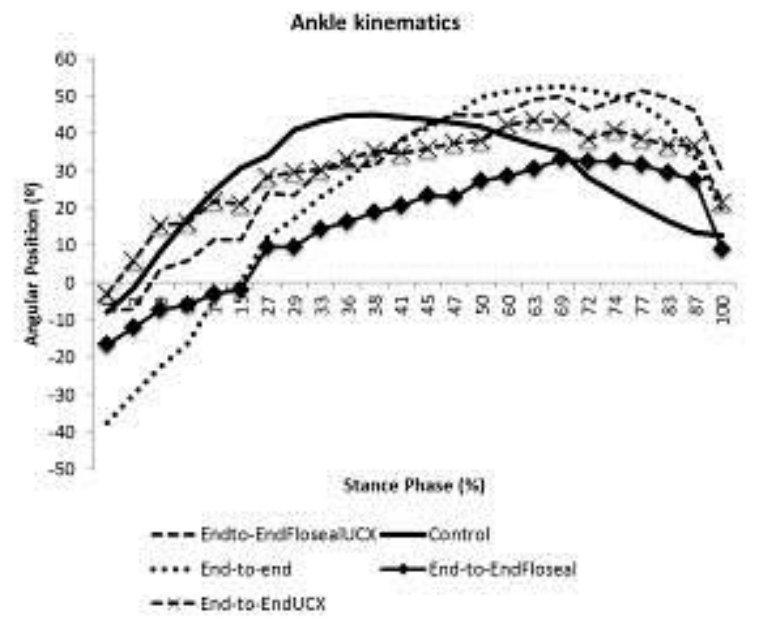

Figure 3 - Kinematic plots. Kinematic plots in the sagittal plane for the ankle angle $\left(^{\circ}\right)$ as it moves through the stance phase, obtained at week 20 after the neurotmesis injury and surgical reconstruction of Control, End-toEnd, End-to-EndFlosealUCX, End-to-EndUCX, and End-to-EndFloseal groups. The mean of each experimental group is plotted $(N=6)$. 


\subsection{Histological and Stereological Analysis}

In the acute phase of the healing period ( 21 days) the samples revealed Wallerian degeneration in varying degrees, from mild to severe, in all material submitted for histology, hindering the observation of axonal regeneration (Figures $4 \mathrm{~A}$ and $4 \mathrm{~B}$ ). A little retraction of the myelin membrane was observed, which could be caused by the nerve injury. However, the fiber organization was higher and the extent of fibrosis was lower in the End-to-EndUCX group (Figures 4A and $4 \mathrm{~B})$.

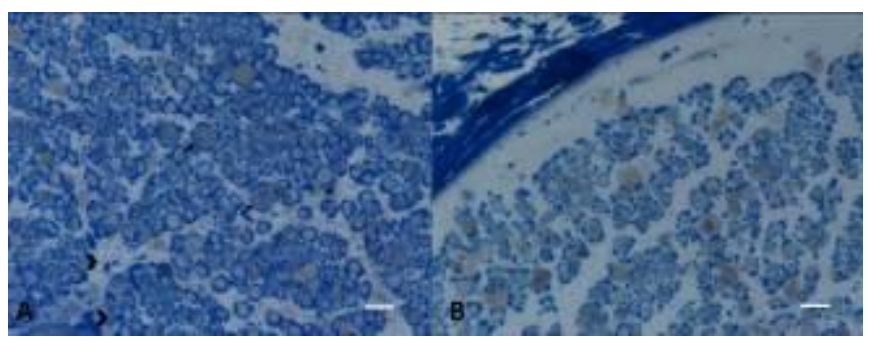

Figure 4 - Histological images: acute phase. Histological analysis of the acute phase of the healing period (day 21 after neurotmesis). Figures $A$ and $B$ show cross sections of epon-embedded rat sciatic nerve from the same experimental group (End-to-EndUCX) with Toluidine Blue stain: Images of Wallerian degeneration - many axons with myelin degeneration (arrowheads) and some regenerating axon clusters (arrows). Original magnification: $400 x$. Scale bar $=10 \mu \mathrm{m}$.

In the hyper-acute phase (3 days), the histology of the Endto-End sample showed disruption of the perineurium, fascicles disorganization, proliferation of Schwann cells with axonal swelling and inflammatory infiltration in the endoneurium. Scarce neutrophils and multinucleated giant cells were also identified, mainly located around hair shafts, probably due to the surgical technique (Figure 5A). In turn, animals belonging to the End-to-EndFloseal and End-toEndFlosealUCX groups developed multiple foci of dystrophic calcification, often accompanied by a foreign body inflammatory reaction (Figures 5B and $5 \mathrm{C}$ ).

In the samples from the End-to-EndFlosealUCX group, this finding was even more prominent and extensive, associated with deposition of large amount of fibrin and hemorrhage which destroyed the normal architecture of the nerve (Figure $5 \mathrm{D}$ ). Mild to moderate amount of mixed inflammatory infiltrate along with elongated mesenchymal cells circumscribing the perineurium were observed in the End-toEndUCX sample (Figure 5C).

Such observations were indicative of an $U C X^{\circledR}$ - mediated induction of Wallerian degeneration necessary for proper nerve regeneration, an assumption that was confirmed by long-term observations (Figure 6) and stereological estimates (Table 1 and Figure 6F). While light microscopy analysis was restrictive, limiting our observations to the expected smaller size of regenerated nerve fibers relative to the controls, stereological analysis disclosed a significantly $(p<0.05)$ larger axon diameter and thicker myelin thickness in the End-toEndFlosealUCX group when compared to either End-to-
EndUCX or End-to-EndFloseal group (Table 1 and Figure $6 \mathrm{~F}$ ). The results clearly demonstrate a synergistic positive effect on regenerated nerve fibers resulting from combined use of $U C X^{\circledast}$ with the Floseal ${ }^{\circledR}$ vehicle.

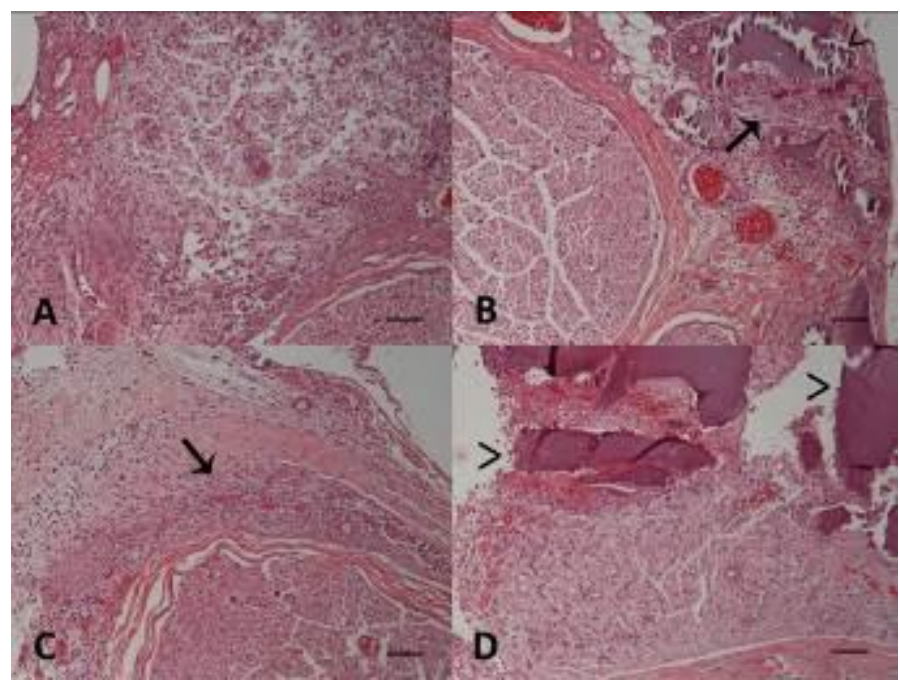

Figure 5 - Histological images: hyper-acute phase. Histological analysis of the hyper-acute phase of the healing period (day 3 after neurotmesis). Cross section of paraffin-embedded rat sciatic nerve, HE: (A) End-to-End: Destruction of perineurium and endoneurium and fascicles disorganization; (B) End-toEndFloseal: multiple foci of calcification (arrowheads) in the epineurium and fatty infiltration, associated with diffuse mononuclear inflammatory infiltrate (arrows); (C) End-to-EndUCX: mild to moderate amount of mixed inflammatory infiltrate (arrows) that circumscribe the perineurium; (D) End-to-EndFlosealUCX: multiple foci of calcification (arrowheads) associated with fibrin deposition and hemorrhage, with destruction of the perineurium and endoneurium. Original magnification: 100x. Scale bar $=50 \mu \mathrm{m}$.
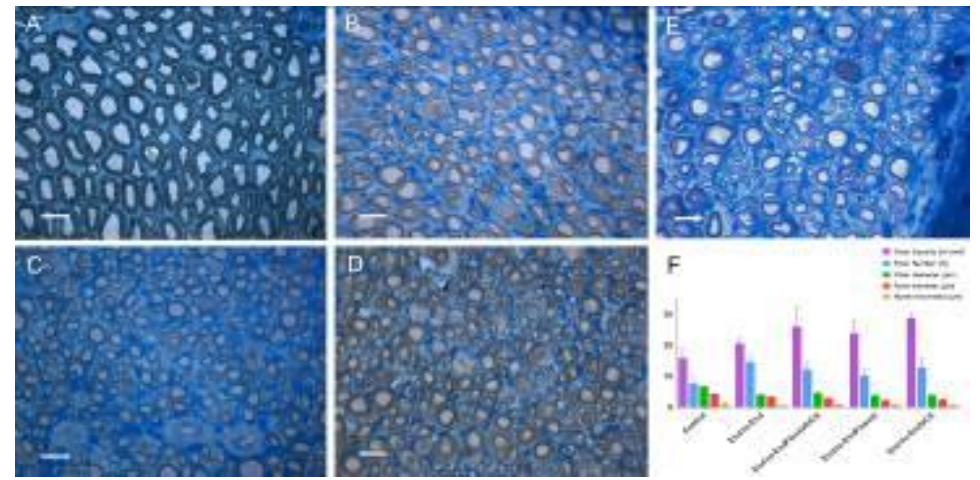

Figure 6 - Light micrographs images and histogram of the stereological parameters.Light micrographs of Toluidine blue-stained sciatic nerve semi-thin sections from four different experimental groups: Control (A) End-to-EndFlosealUCX (B) End-to-EndFloseal (C), End-to-EndCX (D), End-to-End (E). Original magnification: 1000X. Scale bar $=5 \mu \mathrm{m}$. Histogram summarizing results of stereological estimates of density, total number, diameter and myelin thickness in the 4 experimental groups, Control, End-to-EndFlosealUCX, End-to-EndFloseal, End-toEndUCX, and End-to-End at week 20 after neurotmesis. Values are presented as mean $\pm S D(F)$. 
Table 1

\begin{tabular}{|c|c|c|c|c|c|}
\hline Group & $\begin{array}{l}\text { Fiber Density (N } \\
\text { /mm2) }\end{array}$ & $\begin{array}{l}\text { Fiber Number } \\
\text { (N) }\end{array}$ & $\begin{array}{l}\text { Fiber diameter } \\
\qquad(\mu \mathrm{m})\end{array}$ & $\begin{array}{c}\text { Axon diameter } \\
(\mu \mathrm{m})\end{array}$ & $\begin{array}{l}\text { Myelin thickness } \\
\qquad(\mu \mathrm{m})\end{array}$ \\
\hline Control & $15,905 \pm 2,87$ & $7,666 \pm 1,90$ & $6,66 \pm 0,12$ & $4,26 \pm 0,07$ & $1,19 \pm 0,03$ \\
\hline End-to-End & $20,612 \pm 1,607$ & $14,624 \pm 1,642$ & $4,06 \pm 0.30$ & $3,31 \pm 0,09$ & $0,58 \pm 0,03$ \\
\hline End-to-End FlosealUCX & $26,009 \pm 6,512$ & $12,255 \pm 2,290$ & $4,57 \pm 0,51$ & $2,88 \pm 0,42$ & $0,85 \pm 0,05$ \\
\hline End-to-End Floseal & $23,900 \pm 4,291$ & $10,216 \pm 2,040$ & $3,79 \pm 0,30$ & $2,23 \pm 0,21$ & $0,78 \pm 0,06$ \\
\hline End-to-End UCX & $28,821 \pm 1,202$ & $12,925 \pm 2,985$ & $3,89 \pm 0,22$ & $2,42 \pm 0,16$ & $0,77 \pm 0,06$ \\
\hline
\end{tabular}

Table 1 - Stereological quantitative paramaters.

Stereological quantitative assessment of density, total number, diameter and myelin thickness of regenerated sciatic nerve fibers at week-20 after neurotmesis. Values are presented as mean $\pm S D$

\section{Discussion}

Nowadays, most tissue engineered nerve grafts are composed of a neural-scaffold prepared with a variety of biomaterials. The introduction of active cells, delivered by appropriate vehicles, could either replace or add to the system an important biochemical cue. The crucial role of MSCs in tissue renewal and regeneration has been well established ${ }^{[48]}$. UCX ${ }^{\circledR}$ cells in particular have already demonstrated to promote faster remission of local and systemic arthritic manifestations in a chronic adjuvantinduced arthritis model ${ }^{[22]}$. More recently, UCX ${ }^{\circledR}$ grown in aggregates, that better mimic tissue environment, have produced a secretome richer in trophic factors, such as HGF, TGF- $\beta$, G-CSF, VEGF-A, FGF-2, KGF and IL-6, that promote wound healing reactions, as demonstrated both in vitro by vasculogenesis, mitogenic and chemotactic assays, and in vivo, using a chemotaxis assay where $\mathrm{UCX}^{\circledR}$ were shown to recruit surrounding bone marrow MSCs, known to be directly involved in tissue regeneration (results to be published elsewhere).

In the present study the in vivo application of $\mathrm{UCX}^{\circledR}$ was intended to improve the regeneration process in the rat sciatic nerve after a neurotmesis injury which was surgically reconstructed using end-to-end suture. In turn, Floseal ${ }^{\circledR}$ is a biocompatible vehicle which can be easily used and it can be extruded from a syringe and applied topically to the bleeding area. This haemostatic agent has the ability to acquire irregular shapes fitting the wounded site. When the Floseal ${ }^{\circledR}$ is in contact with blood, the collagen particles are hydrated and swell, restricting the blood flow. The thrombin present converts the patient fibrinogen into a fibrin polymer, originating a clot around the lesion area of the nerve ${ }^{[49]}$. We hypothesize that such matrix could partially mimic the natural, physiological matrix of the umbilical cord (Wharton's jelly) from which $U C X^{\circledR}$ cells are extracted, thus promoting three-dimensional (3D) cell-to-cell interactions. As seen by us, $U C X^{\circledR}$ cells grown in $3 D$ spheroid-like structures are primed to a phenotype characterized by a secretome, which is richer in pro-healing factors so, most probably; Floseal ${ }^{\circledR}$ could indeed enhance beneficial 3D UCX ${ }^{\circledR}$ cell-to-cell interactions. Furthermore, the introduction of Floseal ${ }^{\circledR}$ in our chronic model formulation was intended to 1) promote endto-end nerve fiber contacts, and 2) reduce the flush away effect of the cells after administration, thus increasing their permanance within the wounding site. The survival of transplanted MSCs in the injury site was previously reported by other published works. It was known at the starting point of our study that in other disease models characterized by inflammation sites, human MSCs (HMSCs) transiently home and niche to inflammatory sites, remaining viable in a xenotransplated rat for up to approximately 2 weeks in normal mice/rat, increasing their permanance in inflammation sites in diseased models, without detectable homing to other organs. Also, the bio-distribution of placental HMSCs, stably infected with a lentiviral construct expressing the luciferase gene, was performed in both immune-competent and immunecompromised NOD/SCID and Balb/c mice. When $1 \times 10^{6}$ placental HMSCs were administrated, the bio-distribution pattern showed that the cells persisted only at the injection site (intramuscular for peripheral artery disease - PAD model, anterior paw) and did not distribute to other organs. Also, the placental HMSCs retained consistently high levels of luciferase expression, in vitro, for up to 3 weeks [50] Additionally, undifferentiated and differentiated HMSCs from the Wharton's jelly were previously used by our research group in rat sciatic nerve reconstruction after axonotmesis and neurotmesis injuries. Undifferentiated HMSCs transplanted were negatively labelled to glial fibrillary acidic protein (GFAP), growth associated protein-43 (GAP-43), and neuronal nuclei (NeuN) ${ }^{[51]}$ and presented positive effects on the functional and morphological recoveries of peripheral nerve after axonotmesis and neurotmesis. The HMSCs were applied either by local infiltration or associated in monolayer to several biomaterials namely poly(DL-lactide- $\varepsilon$ caprolactone) (PLC) membranes. Other research groups have also proven the positive effects of the HMSCs in peripheral nerve regeneration, where the HMSCs were transplanted to the injury site and survived after the surgical procedure ${ }^{[52-55]}$. The risk of immune rejection in our experimental setup was considered minimal since UCX ${ }^{\circledR}$ cells have been xeno-implanted before into rabbits, rats and sheep without eliciting any compromising immune rejection $[22,56]$. Due to the large importance of the Wallerian degeneration for subsequent cellular and molecular events that lead to nerve regeneration, it was important to evaluate the immediate Wallerian response and early nerve regeneration in the hyper-acute and acute phases, respectively. When an axon is transected, the distal cytoskeleton disintegrates, its cell membrane disappears, and the axon fragments. 
The Wallerian degeneration is accompanied by macrophages entering the transected area to remove myelin and axonal debris being first detected by light microscopy 36 to $44 \mathrm{~h}$ after nerve transection in mice and rats, and reaching a peak around the third week. In the acute phase of the healing, our samples revealed Wallerian degeneration in varying degrees, from mild to severe, hindering the observation of axonal regeneration. On the other hand, nerve fiber organization was higher and the extent of fibrosis was lower when sciatic nerves were treated with $\mathrm{UCX}^{\circledR}$, which suggests the importance of these cells in improving nerve regeneration when applied in the first days after neurotmesis, apparently by promoting a more efficient Wallerian degeneration. Theoretical repercussion of these histological observations performed during the hyper-acute and acute phases were confirmed by long-term observations and stereological estimates. While light microscopy limited the analysis to the observation of the expected smaller size of regenerated nerve fibers, stereological analysis was able to disclose a significantly larger axon diameter and higher myelin thickness in the End-to-EndFlosealUCX group, when compared to the End-to-EndUCX and End-to-EndFloseal experimental groups. These histological and histomorphometric analyses performed in the hyper-acute, acute and chronic phases also suggest that Floseal $^{\circledR}$ is an appropriate vehicle to deliver $\mathrm{UCX}^{\circledR}$ to peripheral nerve injuries.

The myelin sheath was thicker in the regenerated nerves of $\mathrm{UCX}{ }^{\circledR}$-treated animals, suggesting that $\mathrm{UCX}^{\circledR}$ might exert their positive effects on Schwann cells, the key element in Wallerian degeneration and consequent axonal regeneration. Previous results have demonstrated that the use of either undifferentiated or neuroglial-like differentiated Wharton jelly MSCs did enhance the recovery of sensory and motor function of the rat sciatic nerve in axonotmesis and neurotmesis injuries [11,57]. In turn, the degree of acute affection in thermal and nociceptive sensitive function as well as the rate of its recovery in the acute phase in the End-toEnd group was similar to the End-to-EndUCX. Concerning EPT and WRL results in the chronic phase study, no differences in recovery were found between any of the treated groups. However, these tests are, to some extent, more dependent on the operator and therefore subject to human error. Potential pitfalls of the EPT do exist. It takes a certain training period for the tester to become comfortable handling the animals, and this comfort level is critical for the animal to behave in an unfrightened way. There is also a level of recognition of when the animal is bearing its maximum weight, which is critical since the tester is supporting the body of the animal at all times. Also, it was observed autotomy and contractures in the treated animals, which limited the EPT test execution, although the application of a deterrent substance to the animals' right paw every 2 days. As a result, the use of different methods for an overall assessment of nerve function has long been recommended by several investigators ${ }^{[58]}$. In our lab we complement EPT and WRL techniques with a kinematics evaluation in order to reliably predict the potential therapeutic benefit of a nerve repair strategy. In this case, the kinematics analysis showed differences in ankle joint angle between experimental groups. At the instant of IC, the ankle joint angle determined for animals belonging to the End-to-End group was significantly different from any of the remaining treated groups. At OT, which occurs around $20 \%$ of the entire stance phase duration, differences were now found between the End-toEnd group and the groups treated with $\mathrm{UCX}^{\circledR}$ (End-toEndUCX group), and $\mathrm{UCX}^{\circledR}$ administered with Floseal ${ }^{\circledR}$ (End-to-EndFlosealUCX), as well as between the two latter groups. At the instant of HR, meaning the time during the stance phase of the animal's gait cycle, when the push off action begins, significant differences in ankle joint angle were measured between End-to-EndFloseal animals and End-toEndFlosealUCX animals. Despite ankle kinematics did not demonstrate clear differences between groups in terms of functional recovery; it is worthwhile noting that 20 weeks following sciatic nerve neurotmesis the ankle kinematics during the gait stance phase was similar to that of control animals. Because, it is unlikely that sciatic-injured animals can fully restore the normal ankle joint motion pattern during gait, we have to consider that our kinematics analysis might not have sufficient sensitivity to detect small differences in gait performance between experimental groups.

\section{Conclusions}

The histological analysis of the acute phase studies revealed that in the group treated with $\mathrm{UCX}^{\circledR}$ alone the Wallerian degeneration was improved for the subsequent process of regeneration, the fiber organization was higher, and the extent of fibrosis was lower. The chronic phase experimental groups revealed that treatment with $\mathrm{UCX}^{\circledR}$ induced an increased number of regenerated fibers and thickening of the myelin sheet.

Kinematics analysis showed that the ankle joint angle determined for untreated animals was significantly different from any of the treated groups at the instant of IC. At OT and $H R$, differences were found between untreated animals and the groups treated with either $\mathrm{UCX}^{\circledR}$ alone or $\mathrm{UCX}^{\circledR}$ administered with Floseal $^{\circledR}$. Overall, the UCX ${ }^{\circledR}$ application presented positive effect in functional and morphologic recovery in both acute and chronic phases of the regeneration process. Kinematics analysis has revealed positive synergistic effects brought by Floseal $^{\circledR}$ as cell vehicle.

Additionally, further studies will be necessary to clarify the potential of these cells in nerve and tissue regeneration. However, the results discussed herein show a promising effect of $U C X^{\circledR}$ in promoting myelin production in surgically reconstructed nerves after a neurotmesis injury. This effect was observed with human cells in rats and therefore, a more pronounced effect is expected in humans. A new gateway it, therefore, opened for using these cells in neurodegenerative diseases that are typified by demyelination.

\section{References:}

1. Amado S, Simoes MJ, Armada da Silva PA, Luis AL, Shirosaki $Y$, Lopes MA, Santos JD, Fregnan $F$, Gambarotta G, Raimondo S, Fornaro M, Veloso AP, Varejão AS, Maurício AC, Geuna S. Use of hybrid chitosan membranes and N1E-115 cells for promoting nerve regeneration in an axonotmesis rat model. Biomaterials 2008;29(33):4409-19.

2. Mackinnon SE, Hudson AR, Hunter DA. Histologic assessment of nerve regeneration in the rat. Plast Reconstr Surg 1985;75(3):384-8. 
3. Ronchi G, Nicolino S, Raimondo S, Tos P, Battiston B, Papalia I, Varejão AS, Giacobini-Robecchi MG, Perroteau I, Geuna S. Functional and morphological assessment of a standardized crush injury of the rat median nerve. Journal of Neuroscience Methods 2009;179(1):51-7.

4. Chen CJ, Ou YC, Liao SL, Chen WY, Chen SY, Wu CW, Wang CC, Wang WY, Huang YS, Hsu SH. Transplantation of bone marrow stromal cells for peripheral nerve repair. Exp Neurol 2007;204(1):443-53.

5. Schlosshauer B, Muller E, Schroder B, Planck H, Muller HW. Rat Schwann cells in bioresorbable nerve guides to promote and accelerate axonal regeneration. Brain Res 2003;963(1-2):321-6.

6. Keilhoff G, Goihl A, Langnase K, Fansa H, Wolf G Transdifferentiation of mesenchymal stem cells into Schwann cell-like myelinating cells. Eur $\mathrm{J}$ Cell Biol 2006;85(1):11-24

7. Strioga M, Viswanathan S, Darinskas A, Slaby O, Michalek J. Same or Not the Same? Comparison of Adipose TissueDerived Versus Bone Marrow-Derived Mesenchymal Stem and Stromal Cells. Stem Cells Dev 2012;21(14):2724-52..

8. Pittenger MF, Mackay AM, Beck SC, Jaiswal RK, Douglas R, Mosca JD, Moorman MA, Simonetti DW, Craig S, Marshak DR. Multilineage potential of adult human mesenchymal stem cells. Science 1999;284(5411):143-7.

9. Deng W, Obrocka M, Fischer I, Prockop DJ. In vitro differentiation of human marrow stromal cells into early progenitors of neural cells by conditions that increase intracellular cyclic AMP. Biochem Biophys Res Commun 2001;282(1):148-52.

10. Woodbury D, Schwarz EJ, Prockop DJ, Black IB. Adult rat and human bone marrow stromal cells differentiate into neurons. J Neurosci Res 2000;61(4):364-70.

11. Grimpe B, Silver J. The extracellular matrix in axon regeneration. Prog Brain Res 2002;137:333-49.

12. Dezawa M, Takahashi I, Esaki M, Takano M, Sawada H. Sciatic nerve regeneration in rats induced by transplantation of in vitro differentiated bone-marrow stromal cells. Eur J Neurosci 2001;14(11):1771-6.

13. Ladak A, Olson J, Tredget EE, Gordon T. Differentiation of mesenchymal stem cells to support peripheral nerve regeneration in a rat model. Exp Neurol 2011;228(2):242-52.

14. Fu Y-S, Cheng Y-C, Lin M-YA, Cheng H, Chu P-M, Chou S$\mathrm{C}$, Shih $\mathrm{YH}$, Ko MH, Sung MS. Conversion of Human Umbilical Cord Mesenchymal Stem Cells in Wharton's Jelly to Dopaminergic Neurons In Vitro: Potential Therapeutic Application for Parkinsonism. Stem Cells 2006;24(1):115-24.

15. Mitchell KE, Weiss ML, Mitchell BM, Martin P, Davis D, Morales L, Helwig B, Beerenstrauch M, Abou-Easa K, Hildreth T, Troyer D, Medicetty S. Matrix cells from Wharton's jelly form neurons and glia. Stem Cells 2003;21(1):50-60.

16. Sarugaser R, Lickorish D, Baksh D, Hosseini MM, Davies JE. Human Umbilical Cord Perivascular (HUCPV) Cells: A Source of Mesenchymal Progenitors. Stem Cells 2005;23(2):220-9.

17. Wang JF, Wang LJ, Wu YF, Xiang $Y$, Xie CG, Jia BB, Harrington J, McNiece IK. Mesenchymal stem/progenitor cells in human umbilical cord blood as support for ex vivo expansion of CD34(+) hematopoietic stem cells and for chondrogenic differentiation. Haematologica 2004;89(7):837-44.

18. Weiss ML, Medicetty S, Bledsoe AR, Rachakatla RS, Choi M, Merchav S, Luo Y, Rao MS, Velagaleti G, Troyer D. Human Umbilical Cord Matrix Stem Cells: Preliminary Characterization and Effect of Transplantation in a Rodent Model of Parkinson's Disease. Stem Cells 2006;24(3):78192.

19. Weiss ML, Mitchell KE, Hix JE, Medicetty S, El-Zarkouny SZ, Grieger D, Troyer DL. Transplantation of porcine umbilical cord matrix cells into the rat brain. Exp Neurol 2003;182(2):288-99.

20. Meek MF, Coert JH. Clinical use of nerve conduits in peripheral-nerve repair: review of the literature. J Reconstr Microsurg 2002;18(2):97-109.
21. Santos J, Soares R, Martins JP, Basto V, Coelho M, Cruz $\mathrm{P}, \mathrm{Cruz} \mathrm{H}$. Isolation method of precursor cells from human umbilical cord. In: INPI, editor. Portugal: Medinfar, ECBio; 2008.

22. Santos JM, Barcia RN, Simoes SI, Gaspar MM, Calado S, Agua-Doce A, Almeida SC, Almeida J, Filipe M, Teixeira M, Martins JP, Graça L, Cruz ME, Cruz P, Cruz H. The role of human umbilical cord tissue-derived mesenchymal stromal cells $(\mathrm{UCX}(\mathrm{R}))$ in the treatment of inflammatory arthritis. J Transl Med. 2013;11:18.

23. Luis AL, Rodrigues JM, Geuna S, Amado S, Shirosaki $Y$, Lee JM, Fregnan F, Lopes MA, Veloso AP, Ferreira AJ, Santos JD, Armada-Da-silva PA, Varejão AS, Maurício AC. Use of PLGA 90:10 scaffolds enriched with in vitrodifferentiated neural cells for repairing rat sciatic nerve defects. Tissue Eng Part A 2008;14(6):979-93.

24. Oz MC, Rondinone JF, Shargill NS. FloSeal Matrix: new generation topical hemostatic sealant. J Card Surg. 2003;18(6):486-93.

25. Weaver FA, Hood DB, Zatina M, Messina L, Badduke B. Gelatin-thrombin-based hemostatic sealant for intraoperative bleeding in vascular surgery. Annals of vascular surgery 2002;16(3):286-93.

26. Lobato J, Hussain NS, Botelho C, Maurício A, Afonso A, Ali N, Santos JD. Assessment of Bonelike $\AA$ graft with a resorbable matrix using an animal model. Thin solid films 2006:515:362-7.

27. Tolar J, Le Blanc K, Keating A, Blazar BR. Concise review: hitting the right spot with mesenchymal stromal cells. Stem Cells 2010;28(8):1446-55.

28. Beer GM, Steurer J, Meyer VE. Standardizing nerve crushes with a non-serrated clamp. J Reconstr Microsurg 2001;17(7):531-4.

29. Soleymaninejadian E, Pramanik K, Samadian E. Immunomodulatory properties of mesenchymal stem cells: cytokines and factors. Am J Reprod Immunol. 2012 Jan;67(1):1-8.

30. Thalhammer JG, Vladimirova M, Bershadsky B, Strichartz GR. Neurologic evaluation of the rat during sciatic nerve block with lidocaine. Anesthesiology 1995;82(4):1013-25.

31. Amado S, Rodrigues JM, Luis AL, Armada-da-Silva PA, Vieira M, Gartner A, Simões MJ, Veloso AP, Fornaro M, Raimondo S, Varejão AS, Geuna S, Maurício AC. Effects of collagen membranes enriched with in vitro-differentiated $\mathrm{N} 1 \mathrm{E}-115$ cells on rat sciatic nerve regeneration after endto-end repair. J Neuroeng Rehabil 2010;7:7.

32. Gärtner A, Pereira $T$, Simões MJ, Armada-da-Silva $P$, França ML, Sousa R, Bompasso $S$, Raimondo $S$, Shirosaki Y, Nakamura Y, Hayakawa S, Osakah A, Porto B, Luís AL, Varejao ASP, Maurício AC. Use of hybrid chitosan membranes and MSC cells for promoting nerve regeneration in an axonotmesis rat model. Neural Regeneration Research (in press) 2012.

33. Koka R, Hadlock TA. Quantification of functional recovery following rat sciatic nerve transection. Experimental neurology 2001;168(1):192-5.

34. Maurício AC, Gärtner A, Armada-da-Silva $P$, Amado $S$, Pereira T, Veloso AP, Varejao A, Luis AL, Geuna S. Cellular Systems and Biomaterials for Nerve Regeneration in Neurotmesis Injuries. In: Pignatello R, editor. Biomaterials Applications for Nanomedicine ISBN: 978953-307-661-4, , Available from: : InTech; 2011.

35. Masters DB, Berde CB, Dutta SK, Griggs CT, Hu D, Kupsky W, Langer R. Prolonged regional nerve blockade by controlled release of local anesthetic from a biodegradable polymer matrix. Anesthesiology 1993;79(3):340-6.

36. Gärtner A, Pereira T, Simões MJ, Armada-da-Silva PAS, Franja ML, Sousa R, Bompasso S, Raimondo S, Shirosaki Y, Nakamura Y, Hayakawa S, Osakah A, Porto B, Luís AL, Varejao ASP, Maurício AC. Use of hybrid chitosan membranes and human mesenchymal stem cells from the Wharton jelly of umbilical cord for promoting nerve regeneration in an axonotmesis rat model. Neural Regeneration Research 2012;7(29). 
37. Shir $Y$, Zeltser R, Vatine JJ, Carmi G, Belfer I, Zangen A, Overstreet D, Raber $P$, Seltzer Z. Correlation of intact sensibility and neuropathic pain-related behaviors in eight inbred and outbred rat strains and selection lines. Pain 2001;90(1-2):75-82.

38. Varejao AS, Cabrita AM, Meek MF, Bulas-Cruz J, MeloPinto P, Raimondo S, Geuna S, Giacobini-Robecchi MG. Functional and morphological assessment of a standardized rat sciatic nerve crush injury with a non-serrated clamp. Journal of neurotrauma 2004;21(11):1652-70.

39. Varejao AS, Melo-Pinto P, Meek MF, Filipe VM, Bulas-Cruz J. Methods for the experimental functional assessment of rat sciatic nerve regeneration. Neurological research 2004;26(2):186-94.

40. Varejao AS, Cabrita AM, Meek MF, Bulas-Cruz J, Filipe VM, Gabriel RC, Ferreira AJ, Geuna S, Winter DA. Ankle kinematics to evaluate functional recovery in crushed rat sciatic nerve. Muscle Nerve 2003;27(6):706-14.

41. Dijkstra JR, Meek MF, Robinson PH, Gramsbergen A. Methods to evaluate functional nerve recovery in adult rats: walking track analysis, video analysis and the withdrawal reflex. J Neurosci Methods 2000;96(2):89-96.

42. Varejao AS, Cabrita AM, Meek MF, Bulas-Cruz J, Gabriel RC, Filipe VM, Melo-Pinto P, Winter DA. Motion of the foot and ankle during the stance phase in rats. Muscle Nerve 2002;26(5):630-5.

43. Raimondo S, Fornaro M, Di Scipio F, Ronchi G, GiacobiniRobecchi MG, Geuna S. Chapter 5: Methods and protocols in peripheral nerve regeneration experimental research: part II-morphological techniques. Int Rev Neurobiol 2009;87:81103.

44. Scipio FD, Raimondo S, Tos P, Geuna S. A simple protocol for paraffin-embedded myelin sheath staining with osmium tetroxide for light microscope observation. Microscopy Research and Technique 2008;71(7):497-502.

45. Geuna S, Gigo-Benato D, Rodrigues Ade C. On sampling and sampling errors in histomorphometry of peripheral nerve fibers. Microsurgery 2004;24(1):72-6.

46. Geuna S, Tos P, Battiston B, Guglielmone R. Verification of the two-dimensional disector, a method for the unbiased estimation of density and number of myelinated nerve fibers in peripheral nerves. Ann Anat 2000;182(1):23-34.

47. Dominici M, Le Blanc K, Mueller I, Slaper-Cortenbach I, Marini $F$, Krause $D$, Deans $R$, Keating A, Prockop Dj, Horwitz E. Minimal criteria for defining multipotent mesenchymal stromal cells. The International Society for Cellular Therapy position statement. Cytotherapy 2006;8(4):315-7.

48. Parekkadan B, Milwid JM. Mesenchymal stem cells as therapeutics. Annu Rev Biomed Eng 2010;12:87-117.
49. Lobato J, Hussain NS, Botelho C, Rodrigues J, Luis A, Maurício AC, Lopes MA, Santos JD. Assessment of the potential of Bonelike ${ }^{\circledR}$ graft for bone regeneration by using an animal model. Key Engineering Materials 2005;284:877-80.

50. Prather WR, Toren A, Meiron M, Ofir R, Tschope C, Horwitz EM. The role of placental-derived adherent stromal cell (PLX-PAD) in the treatment of critical limb ischemia. Cytotherapy 2009;11(4):427-34.

51. Gärtner A, Pereira T, Armada-da-Silva PAS, Amorim I, Gomes R, Ribeiro J, França ML, Lopes C, Carvalho RA, Socorro S, Oliveira PF, Porto B, Sousa R, Bombaci A, Ronchi G, Fregnan F, Varejão AS, Luís AL, Geuna $S$, Maurício AC. Use of poly(DL-lactide- $\varepsilon$-caprolactone) membranes and mesenchymal stem cells from the Wharton's jelly of the umbilical cord for promoting nerve regeneration in axonotmesis: In vitro and in vivo analysis. Differentiation 2012;84(5):355-65.

52. Sakar M, Korkusuz $P$, Demirbilek M, Cetinkaya DU, Arslan S, Denkbaş EB, Temuçin CM, Bilgiç E, Hazer DB, Bozkurt G. The effect of poly(3-hydroxybutyrate-co-3hydroxyhexanoate) (PHBHHx) and human mesenchymal stem cell (hMSC) on axonal regeneration in experimental sciatic nerve damage. The International journal of neuroscience 2013.

53. Zheng L, Cui HF. Enhancement of nerve regeneration along a chitosan conduit combined with bone marrow mesenchymal stem cells. J Mater Sci Mater Med 2012;23(9):2291-302.

54. Zhao C, Fancy SP, Magy L, Urwin JE, Franklin RJ. Stem cells, progenitors and myelin repair. Journal of Anatomy 2005;207(3):251-8.

55. Yang C-C, Wang J, Chen S-C, Hsieh Y-L. Synergistic effects of low-level laser and mesenchymal stem cells on functional recovery in rats with crushed sciatic nerves. Journal of tissue engineering and regenerative medicine 2013:n/a-n/a.

56. Kalinina NI, Sysoeva VY, Rubina KA, Parfenova YV, Tkachuk VA. Mesenchymal stem cells in tissue growth and repair. Acta naturae 2011;3(4):30-7.

57. Marreco PR, da Luz Moreira P, Genari SC, Moraes AM. Effects of different sterilization methods on the morphology, mechanical properties, and cytotoxicity of chitosan membranes used as wound dressings. J Biomed Mater Res B Appl Biomater 2004;71(2):268-77.

58. Nichols CM, Myckatyn TM, Rickman SR, Fox IK, Hadlock T, Mackinnon SE. Choosing the correct functional assay: a comprehensive assessment of functional tests in the rat. Behav Brain Res 2005;163(2):143-58.

\section{Abbreviations:}

$\begin{array}{ll}{\left[\mathrm{Ca}^{2+}\right]:} & \text { intracellular free } \mathrm{Ca}^{2+} \text { concentration } \\ \text { ATMP: } & \text { advanced therapy medicinal product } \\ \text { BM-MSCs: } & \text { bone marrow derived-mesenchymal stem cells } \\ \text { CD: } & \text { cluster of differentiation } \\ \text { EEPT: } & \text { experimental extensor postural thrust } \\ \text { EPT: } & \text { extensor postural thrust } \\ \text { FBS: } & \text { fetal bovine serum } \\ \text { HR: } & \text { heel rise } \\ \text { i.m.: } & \text { intra-muscular } \\ \text { IC : } & \text { initial contact } \\ \text { MHC: } & \text { major histocompatibility complex } \\ \text { MSCs: } & \text { mesenchymal stem cells } \\ \text { NEPT: } & \text { normal extensor postural thrust } \\ \text { OT: } & \text { opposite toe-off } \\ \text { SD: } & \text { standard desviation } \\ \text { TGF- } \beta 1: & \text { transforming growth factor - beta 1 } \\ \text { TO: } & \text { toe-off } \\ \text { UC-MSCs: } & \text { umbilical cord tissue-derived mesenchymal stem cells } \\ \text { WRL: } & \text { withdrawal reflex latency }\end{array}$




\section{Potential Conflicts of Interests:}

Author Bárcia RN is the head of R \& D of ECBio - Research and Development in Biotechnology S.A., Author Cruz P is a share holder and chief scientific officer (CSO) of ECBio - Research and Development in Biotechnology S.A, Author Cruz H is a share holder and chief executive officer (CEO) of ECBio - Research and Development in Biotechnology S.A., Author Santos JM is the Chief Operations Officer (COO) of ECBio - Research and Development in Biotechnology S.A.

\section{Acknowledgements:}

The authors would like to acknowledge the financial support from Project TRIBONE, № 11458, co-financed by the European Community FEDER fund through ON2 - O Novo Norte - North Portugal Regional Operational Program 2007-2013 and from the program COMPETE - Programa Operacional Factores de Competitividade, project Pest-OE/AGR/UI0211/2011, from projects QREN I\&DT Cluster in Development of Products for Regenerative Medicine and Cell Therapies- Projects Biomat \& Cell QREN 2008/1372 and ECBio QREN 2008/1467, complemented with ECBio S.A. own research funds. Andrea Gartner has a Doctoral grant from Fundação para a Ciência e Tecnologia (FCT) do Ministério da Educação e da Ciência SFRH/BD/70211/2010. The authors would like to acknowledge the financial support from project PTDC/SAUTOX/110457/2009 from FCT and from project "Hybrid Nanostructured Hydrogels: Bone regeneration using Multifunctional injectable Hydrogels - Rebone" - ENMED/0002/2010 from Fundação para a Ciência e Tecnologia (FCT), Ministério da Educação e da Ciência and Program Project Euronanomed, Ref: EraNet - EuroNanoMed JTC2010.

\section{Correspondence to be addressed to:}

Prof. Ana Colette Maurício, Instituto de Ciências Biomédicas Abel Salazar (ICBAS), Universidade do Porto (UP), Rua de Jorge Viterbo Ferreira, n 228, 4050-313 Porto, Portugal.

Mobile: +351.91 .9071286 ; Phone: +351.22 .0428000 ;

Email: ana.colette@hotmail.com, acmauricio@icbas.up.pt 